\title{
Phase Angle and Dry Weight Benefit Nutritional Management of a Patient with Primary Myelofibrosis Undergoing Allogeneic Hematopoietic Stem Cell Transplantation
}

\author{
Isabelle Novelli ${ }^{a} \quad G^{2}$ iancarlo Fatobene ${ }^{b} \quad$ Ana Carolina Silva ${ }^{c}$ \\ Ana Lucia Rodrigues ${ }^{c} \quad$ Ariane Severine $^{c}$ Vanderson Rocha ${ }^{b}$ \\ Erika Yuri Hirose ${ }^{c}$ \\ aMultiprofessional Residency in Cancer Patient Care, Sírio-Libanês Hospital, \\ São Paulo, Brazil; bBone Marrow Transplantation Unit, Sírio-Libanês Hospital, \\ São Paulo, Brazil; ' Oncology Center, Sírio-Libanês Hospital, São Paulo, Brazil
}

\section{Keywords}

Primary myelofibrosis - Hematopoietic stem cell transplantation - Body composition · Cancer · Malnutrition

\begin{abstract}
Background: Progressive, involuntary weight loss $(\mathrm{WL})$ is common in patients with primary myelofibrosis (PMF), and the etiology of this manifestation is multifactorial. A triad of ascites, edema, and splenomegaly is common; therefore, the body weight may be overestimated due to fluid overload. A comprehensive nutritional assessment, including measurement of dry weight, is necessary for monitoring disease progression and to allow the effective planning of nutritional interventions. Also, the phase angle (PA) has been suggested as an important prognostic and muscle mass marker in patients with cancer. To date, there have been no reports of
\end{abstract}




\section{Case Reports in Clinical Nutrition} \begin{tabular}{l|l} 
Case Rep Clin Nutr 2019;2:16-20 \\
\hline DOI: 10.1159/000498982 & $\begin{array}{l}\text { ( 2019 The Author(s). Published by S. Karger AG, Basel } \\
\text { www.karger.com/crc }\end{array}$
\end{tabular}

Novelli et al.: PA and Dry Weight Benefit Nutritional Management of a Patient Undergoing HSCT

bioimpedance analysis (BIA) of patients with PMF. Case Presentation: A 56-year-old man with PMF underwent allogeneic hematopoietic stem cell transplantation (HSCT) with fatigue and postprandial abdominal fullness, exhibiting splenomegaly $(>10 \mathrm{~cm})$ and bilateral lower-extremity edema. On day -13 , a BIA was performed. The patient had a body weight of $73.5 \mathrm{~kg}$, with a fluid balance of $+9.2 \mathrm{~L}$ and a $\mathrm{PA}$ at $50 \mathrm{kHz}$ of $3.15^{\circ}$. A nutritional intervention was administered for 26 days, and on day +13 of HSCT, a repeat BIA revealed an estimated body weight of $69.7 \mathrm{~kg}$ with a fluid balance of $+5.8 \mathrm{~L}$ and a PA at $50 \mathrm{kHz}$ of $3.17^{\circ}$, as well as nonsignificant WL (3.1\% in 1 month). Conclusions: This case report is an important addition to the nutritional assessment of PFM patients, since we could provide a better nutritional intervention due to our understanding of the estimated dry weight and assess the PA to investigate a new element of prognosis. Additional studies are needed to demonstrate the effectiveness of BIA in these patients.

(C) 2019 The Author(s)

Published by S. Karger AG, Basel

\section{Introduction}

Progressive, involuntary weight loss (WL) is common in patients with primary myelofibrosis (PMF) - a clonal stem cell disorder classified within the group of $B C R / A B L$-negative chronic myeloproliferative neoplasms $[1,2]$. The etiology of this manifestation is multifactorial, and includes increased levels of proinflammatory cytokines, abdominal pain and enlargement, early satiety, and decreased oral intake. A triad of ascites, edema, and splenomegaly is common in these patients [3]. Therefore, the body weight may be overestimated due to fluid overload. Due to the many complicated factors of PMF, it is difficult to estimate the dry weight.

Hematopoietic stem cell transplantation (HSCT) is the only curative treatment for myelofibrosis. Patients undergoing HSCT usually are at nutritional risk due to side effects of the disease and the conditioning regimen. Fuji et al. [4] demonstrated that underweight patients had a poorer overall survival due to the risk of relapse. Also, a $10 \% \mathrm{WL}$ after allogenic HSCT (alloHSCT) was associated with worse clinical outcome [5]. This evidence demonstrates the importance of a comprehensive nutritional assessment, including measurement of dry weight, which is necessary for monitoring disease progression and to allow effective planning of nutritional interventions [6].

An electrical bioimpedance analysis (BIA) is used to measure resistance (R) and reactance (Xc) of individuals. With the application of these values, it is possible to estimate the fluid status and, therefore, dry weight [7]. Another important parameter is the phase angle (PA), that is, the ratio between reactance and resistance, which has been suggested as a prognostic marker for patients with cancer [8-10] and an important prognostic value in alloHSCT [11]. The PA is a marker of cell mass and membrane integrity; it correlates positively with muscle mass and negatively with survival. The PA is considered low if $<5.0^{\circ}$ in men or $<4.6^{\circ}$ in women [10].

To date, there have been no reports on the use of BIA for patients with PMF; thus, the aim of this case report was to assess the PA and estimated dry weight in order to understand the nutritional status and prognosis and to formulate an adequate nutritional intervention. 


\section{Case Reports in Clinical Nutrition}

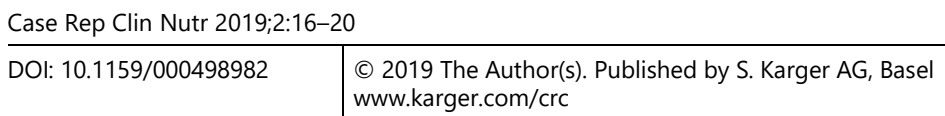
www.karger.com/crc

Novelli et al.: PA and Dry Weight Benefit Nutritional Management of a Patient Undergoing HSCT

\section{Case Presentation}

A 56-year-old man was diagnosed with PMF in 2013. Due to the low risk of the disease and absence of a $\mathrm{JAK}_{2}$ mutation, a watchful-waiting approach was adopted. In 2016, the patient reported the onset of constitutional symptoms of PMF, including WL, abdominal fullness, abdominal distension, and fatigue. In February 2017, the patient reported worsening symptoms, and a bone marrow biopsy revealed $10 \%$ blasts. Ruxolitinib was started, but discontinued after 4 months due to lack of response. In June 2017, the patient was admitted with $20.7 \%$ peripheral blood blasts and scheduled to undergo unrelated-donor alloHSCT.

On the day of admission (day -16), the patient complained of fatigue and postprandial abdominal fullness, exhibiting splenomegaly $(>10 \mathrm{~cm})$ and bilateral lower-extremity edema. He was classified at nutritional risk due to progressive $W L$, low oral intake according to food recall, and signs of severe muscle mass and adipose tissue depletion on physical examination.

For a more accurate determination of the patient's actual weight, tetrapolar BIA was performed (Body Composition Monitor; Fresenius Medical Care, Germany) on day -13 . The patient's wet weight was $73.5 \mathrm{~kg}$ and the BMI was $20.6 \mathrm{~kg} / \mathrm{m}^{2}$, which would correspond to normal weight (Table 1). However, the patient's estimated dry weight was $66.1 \mathrm{~kg}$ (fluid balance +9.2 L; PA at $50 \mathrm{kHz}: 3.15^{\circ}$ ), which changed the BMI to $18.1 \mathrm{~kg} / \mathrm{m}^{2}$ (grade I underweight). The patient's energy and protein intake targets were adjusted to the estimated dry weight, and an enteral nutrition plan was administered to meet the patient's needs. He received a conditioning regimen based on treosulfan, cyclophosphamide, and thymoglobulin, followed by infusion of mobilized peripheral stem cells from an unrelated HLA-matched donor; his graft-versushost disease prophylaxis consisted of cyclosporine and mycophenolate.

On day +13 of HSCT, a repeat BIA revealed an estimated dry weight of $63.9 \mathrm{~kg}$ (fluid balance $+5.8 \mathrm{~L}$; BMI $17.5 \mathrm{~kg} / \mathrm{m}^{2}$ [grade I underweight]; PA at $50 \mathrm{kHz}: 3.17^{\circ}$ ), as well as nonsignificant WL (3.1\% in 1 month) [12]. During the 26 days of follow-up, the patient remained with full energy and protein target support by enteral nutrition without reporting any discomfort. Oral intake was maintained for comfort, but the patient presented a low intake and preferred a thick puree diet. Unfortunately, despite successful hematopoietic engraftment, he developed multiple complications and died of septic shock on day +62 .

\section{Discussion and Conclusion}

At both time points of BIA, the patient was found to be in a state of fluid overload, which corroborates the hypothesis that weight should be evaluated cautiously in patients with PMF. It is clear that in this case, using the BMI - a widely used index - for body weight assessment was not predicting the nutritional status very well. The accurate estimation of dry weight allows the design of reliable interventions and energy and protein intake goals that can benefit the patient, and in our case, it was able to diminish a WL that had been happening progressively for many months and allowed the clinician to monitor the effectiveness of the proposed interventions. Overestimating or underestimating nutritional needs - either of which would be detrimental to patients - would cause pain and discomfort for the extra volume of enteral diet based on the current or incorrect weight. 
Novelli et al.: PA and Dry Weight Benefit Nutritional Management of a Patient Undergoing $\mathrm{HSCT}$

On the first measurement, the PA was already below the recommendations for cancer patients, suggesting a worse prognosis and malnutrition $[13,14]$, which demonstrates the importance of a proper nutritional intervention that targets patients' needs. We observed that the PA demonstrated no significant change between time points; thus, we were able to maintain cell mass and integrity and, therefore, muscle mass, since the PA is an indirect marker. It could be considered a modifiable risk factor in alloHSCT [13], and the outcome that we achieved regarding the PA could possibly be related to the proposed nutritional intervention.

Limitations to the use of BIA include the biases of body composition data (lean mass, fat mass, and hydration), which are an estimation using resistance and reactance values, which in turn can be influenced by the presence of edema and splenomegaly and should thus be considered with caution in this setting. This case report is an important addition to the nutritional assessment of PFM patients, since we could provide a better nutritional intervention due to our understanding of the estimated dry weight at a critical moment of treatment and assess the PA to investigate a new element of the prognosis. Because this is only a case report, additional studies are needed to demonstrate the effectiveness of BIA in these patients, considering the limitations mentioned above, but if a BIA device is available, its use may be considered for monitoring of dry weight and PA, both of which are predictive of clinical outcomes and help with decisions at each moment of treatment, avoiding possible patient suffering related to nutritional therapy.

\section{Statement of Ethics}

This research was approved by the Hospital Sírio-Libanês Ethics Committee under the No. HSL-RC 2017-14.

\section{Disclosure Statement}

The authors have no conflicts of interest to declare.

\section{Author Contributions}

I.N. and E.Y.H. participated in the design of the study and performed the BIA and writing of the article. A.C.S. reviewed data collection and helped with the interpretation of the analysis. A.L.R. and A.S. ensured the quality of the data. G.F. and V.R. participated in revising the final manuscript. All authors read and approved the final manuscript.

\section{References}

1 Mesa RA, Schwager S, Huang J, Hussein K, Pardanani AD, Tefferi A. Dynamics, and prognostic impact, of weight loss in primary myelofibrosis. Blood. 2008;112(11):5224.

2 Cervantes F, Pereira A. Prognostication in primary myelofibrosis. Curr Hematol Malig Rep. 2012 Mar;7(1):43-9. 
Novelli et al.: PA and Dry Weight Benefit Nutritional Management of a Patient Undergoing HSCT

3 Savona MR. Are we altering the natural history of primary myelofibrosis? Leuk Res. 2014 Sep;38(9):100412.

4 Fuji S, Takano K, Mori T, Eto T, Taniguchi S, Ohashi K, et al. Impact of pretransplant body mass index on the clinical outcome after allogeneic hematopoietic SCT. Bone Marrow Transplant. 2014 Dec;49(12):1505-12.

5 Fuji S, Mori T, Khattry N, Cheng J, Do YR, Yakushijin K, et al. Severe weight loss in 3 months after allogeneic hematopoietic SCT was associated with an increased risk of subsequent non-relapse mortality. Bone Marrow Transplant. 2015 Jan;50(1):100-5.

6 de Melo Campos P. Primary myelofibrosis: current therapeutic options. Rev Bras Hematol Hemoter. 2016 Jul-Sep;38(3):257-63.

7 Abbas SR, Zhu F, Levin NW. Bioimpedance can solve problems of fluid overload. J Ren Nutr. 2015 Mar;25(2):234-7.

8 Pérez Camargo DA, Allende Pérez SR, Verastegui Avilés E, Rivera Franco MM, Meneses García A, Herrera Gómez Á, et al. Assessment and Impact of Phase Angle and Sarcopenia in Palliative Cancer Patients. Nutr Cancer. 2017 Nov-Dec;69(8):1227-33.

9 Władysiuk MS, Mlak R, Morshed K, Surtel W, Brzozowska A, Małecka-Massalska T. Bioelectrical impedance phase angle as a prognostic indicator of survival in head-and-neck cancer. Curr Oncol. 2016 Oct;23(5): e481-7.

10 Hui D, Dev R, Pimental L, Park M, Cerana MA, Liu D, et al. Association Between Multi-frequency Phase Angle and Survival in Patients With Advanced Cancer. J Pain Symptom Manage. 2017 Mar;53(3):571-7.

11 Urbain P, Birlinger J, Ihorst G, Biesalski HK, Finke J, Bertz H. Body mass index and bioelectrical impedance phase angle as potentially modifiable nutritional markers are independent risk factors for outcome in allogeneic hematopoietic cell transplantation. Ann Hematol. 2013 Jan;92(1):111-9.

12 Blackburn GL, Bistrian BR, Maini BS, Schlamm HT, Smith MF. Nutritional and metabolic assessment of the hospitalized patient. JPEN J Parenter Enteral Nutr. 1977;1(1):11-22.

13 Ren G, Cai W, Wang L, Huang J, Yi S, Lu L, et al. Impact of body mass index at different transplantation stages on postoperative outcomes in patients with hematological malignancies: a meta-analysis. Bone Marrow Transplant. 2018 Jun;53(6):708-21.

14 Kyle UG, Genton L, Pichard C. Low phase angle determined by bioelectrical impedance analysis is associated with malnutrition and nutritional risk at hospital admission. Clin Nutr. 2013 Apr;32(2):294-9.

Table 1. Electrical bioimpedance analysis findings for hematopoietic stem cell transplantation on days -13 and +13

\begin{tabular}{lll}
\hline & Day -13 & Day +13 \\
\hline $\begin{array}{l}\text { Before electrical bioimpedance } \\
\text { Weight }\end{array}$ & $75.3 \mathrm{~kg}$ & $69.7 \mathrm{~kg}$ \\
BMI & $20.6 \mathrm{~kg} / \mathrm{m}^{2}$ & $19.1 \mathrm{~kg} / \mathrm{m}^{2}$ \\
After electrical bioimpedance & & \\
Weight & $66.1 \mathrm{~kg}$ & $63.9 \mathrm{~kg}$ \\
BMI & $18.1 \mathrm{~kg} / \mathrm{m}^{2}$ & $17.5 \mathrm{~kg} / \mathrm{m}^{2}$ \\
Fluid balance & $+9.2 \mathrm{~L}$ & $+5.8 \mathrm{~L}$ \\
Phase angle at $50 \mathrm{kHz}$ & $3.15^{\circ}$ & $3.17^{\circ}$ \\
\hline
\end{tabular}

